\title{
A chemical analyzer for charged ultrafine particles
}

\author{
S. G. Gonser ${ }^{1,2}$ and A. Held ${ }^{1,2}$ \\ ${ }^{1}$ Junior Professorship in Atmospheric Chemistry, University of Bayreuth, 95440 Bayreuth, Germany \\ ${ }^{2}$ Bayreuth Center of Ecology and Environmental Research, University of Bayreuth, 95440 Bayreuth, Germany
}

Correspondence to: S. G. Gonser (stefan.gonser@uni-bayreuth.de)

Received: 28 March 2013 - Published in Atmos. Meas. Tech. Discuss.: 18 April 2013

Revised: 15 July 2013 - Accepted: 31 July 2013 - Published: 11 September 2013

\begin{abstract}
New particle formation is a frequent phenomenon in the atmosphere and of major significance for the Earth's climate and human health. To date the mechanisms leading to the nucleation of particles as well as to aerosol growth are not completely understood. A lack of appropriate measurement equipment for online analysis of the chemical composition of freshly nucleated particles is one major limitation. We have developed a Chemical Analyzer for Charged Ultrafine Particles (CAChUP) capable of analyzing particles with diameters below $30 \mathrm{~nm}$. A bulk of size-separated particles is collected electrostatically on a metal filament, resistively desorbed and subsequently analyzed for its molecular composition in a time of flight mass spectrometer. We report on technical details as well as characterization experiments performed with the CAChUP. Our instrument was tested in the laboratory for its detection performance as well as for its collection and desorption capabilities. The manual application of defined masses of camphene $\left(\mathrm{C}_{10} \mathrm{H}_{16}\right)$ to the desorption filament resulted in a detection limit between 0.5 and $5 \mathrm{ng}$, and showed a linear response of the mass spectrometer. Flow tube experiments of $25 \mathrm{~nm}$ diameter secondary organic aerosol from ozonolysis of alpha-pinene also showed a linear relation between collection time and the mass spectrometer's signal intensity. The resulting mass spectra from the collection experiments are in good agreement with published work on particles generated by the ozonolysis of alpha-pinene. A sensitivity study shows that the current setup of CAChUP is ready for laboratory measurements and for the observation of new particle formation events in the field.
\end{abstract}

\section{Introduction}

Aerosol particles are of significant relevance for the Earth's radiation balance (Forster et al., 2007) and human health (Delfino et al., 2005; Stieb et al., 2002). It is well known that part of the aerosol forms in the atmosphere through nucleation of gas-phase precursor molecules. The formation of these so-called secondary aerosol particles can be observed in the planetary boundary layer at a multitude of locations around the world both in natural backgrounds as well as in polluted industrial areas (e.g. Kulmala et al., 2004). Typically, particle nucleation events begin in the morning hours and the nucleated particles grow for several hours to a few days by coagulation and condensation, reaching diameters in the order of $100 \mathrm{~nm}$. Typical aerosol growth and nucleation rates are in the range of $1-20 \mathrm{~nm} \mathrm{~h}^{-1}$ and $0.01-10 \mathrm{~cm}^{-3} \mathrm{~s}^{-1}$, respectively (Kulmala et al., 2004). Once the initial nuclei are formed the particles will grow due to condensation of certain trace gases. The main contributors to the growth of particles are thought to be sulfuric acid, oxidation products of volatile organic compounds (VOCs), ammonia salts such as ammonium sulfate and aminium salts, as has been shown by several studies using direct as well as indirect methods (e.g. Barsanti et al, 2009; Held et al., 2004; Laaksonen et al., 2008; Riipinen et al., 2009; Smith et al., 2010). Even though there is a general idea about the mechanisms governing the growth of freshly nucleated particles a lot of processes remain unrevealed. This is due to the challenging task of performing online chemical analysis of sub- $30 \mathrm{~nm}$ particles. The small mass of these ultrafine particles is a limiting factor. For example, a particle of $10 \mathrm{~nm}$ diameter has a mass of a few attograms $\left(10^{-18} \mathrm{~g}\right)$. The preferred method to perform such measurements is the mass spectrometric approach, 
as the achieved detection limits are low enough to analyze chemical components of ultrafine particles.

To date there are two instruments available which are capable of performing online measurements of the chemical composition of sub-30 nm aerosol particles in the field: (I) NAMS - the Nano Aerosol Mass Spectrometer (Wang et al., 2006) and (II) TDCIMS - the Thermal Desorption Chemical Ionization Mass Spectrometer (Voisin et al., 2003). NAMS is capable of measuring the quantitative atomic composition of individual particles down to diameters of $7 \mathrm{~nm}$ (Wang et al., 2006). Its principle of operation is the laser-induced ablation of single particles captured in an ion trap, and the subsequent elemental analysis with a time of flight mass spectrometer (TOF-MS). Due to the high energetic laser pulse the particles break up into ionized atomic elements. Thus, molecular information about the sampled aerosol is not available. The TDCIMS, in contrast, analyzes the molecular composition of a particle bulk of one size range, down to diameters of $6 \mathrm{~nm}$ (Smith et al., 2004). The particles are charged in a unipolar charger, size selected in a differential mobility analyzer (DMA), collected on a filament and subsequently evaporated. The resulting gas is chemically ionized and analyzed for its molecular composition in a triple-quadrupole mass spectrometer, an ion trap mass spectrometer (Held et al., 2009), or a high-resolution time of flight mass spectrometer (Winkler et al., 2012). Both instruments are custom-built. Considering the scarcity of available instrumentation to measure the molecular composition of sub-30 nm particles, we present the design and first measurement results of an additional aerosol mass spectrometer for this size range. In principle, our instrument is similar to the TDCIMS, with a few major differences: firstly, for charging the particles we optionally use a non-radioactive source, thus facilitating the transport of the instrument to field sites in consideration of the transport restrictions regarding radioactive material. Secondly, we use a compact TOF-MS, minimizing the overall size of our instrument while accepting a lower mass resolution. Thirdly, we use electron ionization instead of chemical ionization, resulting in well-known fragmentation of many molecules.

For characterization of the instrument we analyzed particles generated in the laboratory using a $10 \mathrm{~cm}^{3}$ laminar flow tube. Secondary organic aerosol (SOA) was produced by dark ozonolysis of alpha-pinene, resulting in an aerosol size distribution with a mean diameter of $31 \mathrm{~nm}$.

\section{Chemical analyzer for charged ultrafine particles}

The general setup for aerosol collection and desorption of our Chemical Analyzer for Charged Ultrafine Particles (CAChUP) is similar to the TDCIMS. A size-segregated particle sample is collected by electrostatic precipitation and subsequently desorbed for mass spectrometric analysis. Figure 1 shows a sketch of the complete setup: in the charger, ambient aerosol particles are charged either by corona dis-

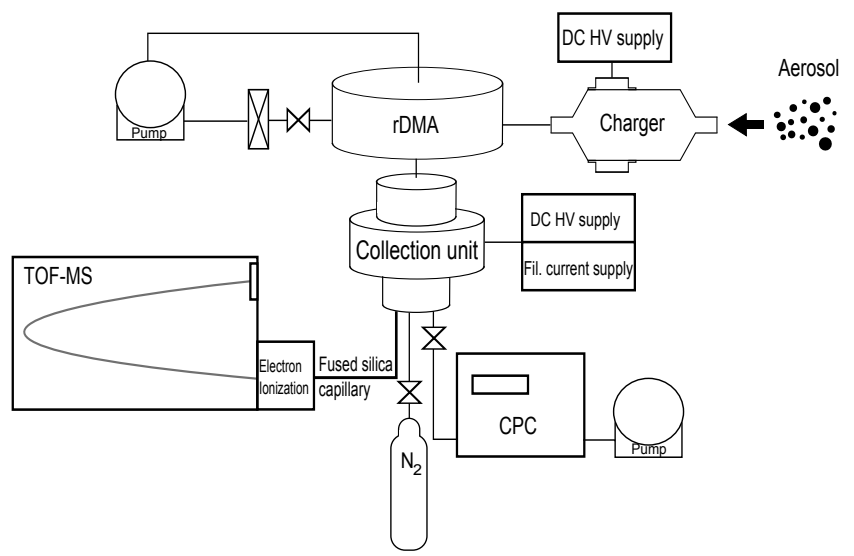

Fig. 1. Sketch of the instrument setup, with particle charging unit, radial differential mobility analyzer (rDMA), collection and desorption unit and electron ionization time of flight mass spectrometer (TOF-MS).

charge or by a radioactive neutralizer. The radial differential mobility analyzer (rDMA) selects particles with a defined mobility diameter, which then are collected on a high voltage biased filament in the collection unit. After the collection period, the sample is evaporated by resistive heating of the filament. The resultant gas phase is transferred via a heated, fused silica capillary to the TOF-MS and ionized by electron impact before mass spectrometric analysis. Following the collection unit, the aerosol flow is measured for its particle concentration with a condensation particle counter (CPC), allowing to determine the collection efficiency as well as to estimate the collected particle mass. The individual parts of the instrument are described in more detail below.

\subsection{Aerosol charging}

For size separation in an rDMA and electrostatic precipitation, aerosol particles have to be electrically charged. Efficient charging of the aerosol is crucial for the overall performance of the mass spectrometer. Due to the small mass of individual nucleation mode particles it is necessary to charge as many particles as possible, in order to collect a sample mass sufficiently large for reliable analysis in the TOF-MS. This depends both on the charging efficiency of the aerosol charger as well as the collection efficiency of the collection filament. Two charging methods have been used with our instrument, i.e. corona discharge-based diffusion charging and bipolar diffusion charging with a radioactive source $(\mathrm{Kr}-85)$.

A corona discharge ionizes the molecules of the carrier gas (ambient air in our case), and these ions pass their charges to the aerosol particles by collision. Corona discharge is generated by applying a high voltage to a conductor with a highly curved surface (e.g. a thin wire or the tip of a needle). The intensity of the corona depends solely on the strength of the resulting electric field in the immediate vicinity of the 
conductor, which is controlled by the curvature of the conductor as well as by the applied voltage.

A corona discharge may also create a considerable amount of ozone, depending on the diameter of the conductor, as well as on the voltage applied to the conductor (Chen and Davidson, 2002; Han et al., 2008). To avoid the chemical alteration of the aerosol sample through oxidation, the production of ozone, $\mathrm{OH}$ and other oxidizing gas phase species has to be prevented or kept as low as possible. The design of our charger is based on the development by Han et al. (2008). In order to produce an efficient corona with a negligible production of oxidizing species, the charger is equipped with two carbon fiber bundles, with about 100 fibers per bundle and a fiber diameter of about $25 \mu \mathrm{m}$, instead of a corona needle. The thin fiber diameter and the large number of fibers comprised in the bundle allows the production of sufficient ions for charging aerosol particles in environmentally relevant concentrations, while still applying relatively low voltages of $2 \mathrm{kV}$, thus minimizing the production of ozone and other oxidants. Only the production of ozone was monitored in the laboratory due to a lack of measuring capabilities for $\mathrm{OH}$ radicals. Ozone mixing ratios were below $1 \mathrm{ppb}$, which is the detection limit of the used ozone monitor (Model 49i, Thermo Scientific, Franklin, MA, USA). Based on these results, the production of other oxidizing species like $\mathrm{OH}$ cannot be excluded but is considered to be small.

A positive DC voltage of $2 \mathrm{kV}$ is applied to the carbon fiber bundles resulting in the production of positive air ions. The aerosol sample is introduced into the charging volume with a flow rate of 1 SLM (standard liter per minute), and the air ions transfer their charges to the particles by collision. The charging efficiency depends strongly on aerosol particle concentration, ion concentration and residence time of the aerosol sample in the charging region. For particle concentrations of about $10^{4} \mathrm{~cm}^{-3}$ and below, and a residence time of $4 \mathrm{~s}$, our corona charger showed an extrinsic charging efficiency of 20 to $30 \%$ for 10 and $20 \mathrm{~nm}$ particles, respectively (cf. Fig. 2). The extrinsic charging efficiency is defined as the number of charged particles exiting the charger divided by the total number of particles entering the charger. Since no sheath flow is used in our charger, the extrinsic charging efficiency is the same as the overall charging efficiency.

A known problem for unipolar charging is the occurrence of multiply charged particles. A doubly charged particle exhibits a larger diameter than the singly charged particle of the same electrical mobility. Hence, both sizes will be selected in the rDMA, and the collected aerosol sample will be contaminated by the larger, doubly charged particles. In fact, under certain experimental conditions we observed considerable double charging of sub- $30 \mathrm{~nm}$ particles with the unipolar corona charger. This observation is consistent with the sizedependent charge distribution of a unipolar charger (Chen and Pui, 1999) shown in McMurry et al. (2009) (Fig. 2). The perturbing influence of doubly charged particles could be minimized by applying a pre-separator prior to the unipo-

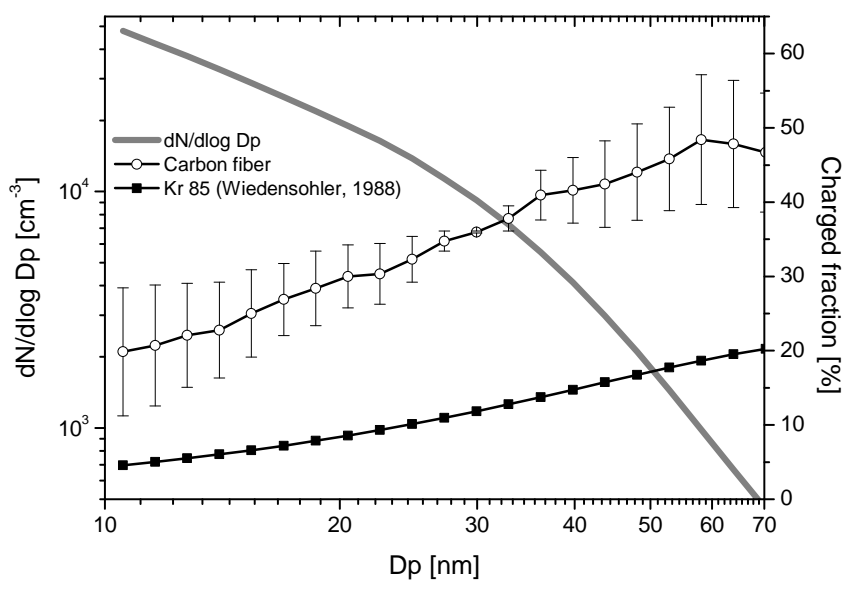

Fig. 2. Size-dependent extrinsic charging efficiency of the unipolar carbon fiber corona charger, and the theoretical charging efficiency of the bipolar charge equilibrium (Wiedensohler, 1988) for singly positive charged particles. Additionally, the number-size distribution of the aerosol used for characterization is shown.

lar charger, preventing particles with diameters above $50 \mathrm{~nm}$ to enter the charger. Otani et al. (2007) report of a metal fiber filter having a high penetration efficiency in the size range between $5 \mathrm{~nm}$ and $50 \mathrm{~nm}$, exhibiting only a small pressure drop of $130 \mathrm{hPa}$. Alternatively, a radioactive bipolar diffusion charger $(\mathrm{Kr}-85)$ can be used to minimize multiple charging of aerosol particles. According to Wiedensohler (1988), particles smaller than $30 \mathrm{~nm}$ in diameter exhibit less than $0.1 \%$ positive double charges in the bipolar charge equilibrium state. However, the radioactive charging results in much lower charging efficiencies than our unipolar design (cf. Fig. 2). For characterization experiments in the laboratory, the radioactive bipolar charger was used with sufficiently high particle concentrations produced in the flow tube and minimized production of doubly charged particles.

\subsection{Aerosol size separation}

Size separation of the aerosol particles was performed with a custom-built radial differential mobility analyzer (rDMA). The rDMA design is adapted from Zhang et al. (1995) and Zhang and Flagan (1996) and optimized to separate particles in the size range $1-100 \mathrm{~nm}$. In principle, the layout of an rDMA is similar to a plate capacitor composed of two separated circular electrodes with central outlets. A voltage is applied to one electrode while the other electrode is grounded, resulting in the formation of a uniform electric field. The charged aerosol particles enter the space between the electrodes from an annular gap at the outer edges with the flow directed radially towards the center, where the sample is extracted at the outlet of the grounded electrode. When an electric field is applied between the electrodes, the charged particles follow distinct trajectories, depending on their electrical mobility and the field strength. Thus, the application of 


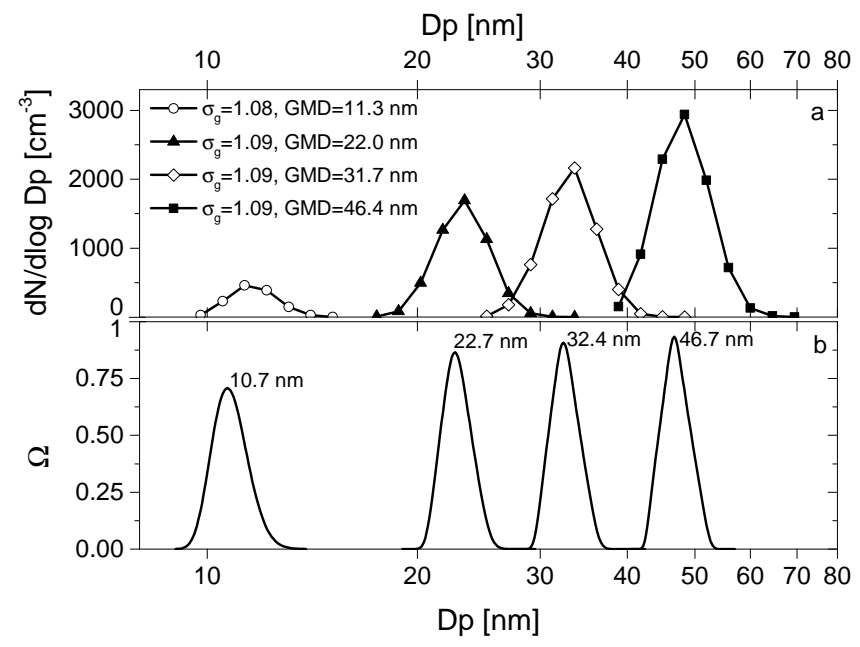

Fig. 3. Comparison of the performance of the rDMA coupled to an SMPS system (a) with theoretical transfer functions (b). A sheath flow of 4 SLM and voltages of 116, 504, 1003 and $2000 \mathrm{~V}$ resulted in geometric mean diameters measured by an SMPS system of 11.3, 22.0, 31.7 and $46.4 \mathrm{~nm}$, respectively. The theoretical transfer functions peak at $10.7,22.7,32.4$ and $46.7 \mathrm{~nm}$, respectively.

a specific electric field strength will result in the selection of particles with a distinct mobility diameter.

In contrast to the original design by Zhang et al. (1995) the spacing of the two electrodes is $9 \mathrm{~mm}$, while the radius between the annular aerosol inlet and the central outlet is $30 \mathrm{~mm}$, shifting the design's operation range towards smaller particles. Flows in the rDMA were set to a sheath flow of 4 SLM and an aerosol flow of 1 SLM. Figure 3 shows the performance of the rDMA in laboratory experiments, by coupling the rDMA to a reference scanning mobility particle sizer (SMPS, TROPOS Leipzig). Charged ambient aerosol was introduced into the rDMA while applying a constant electric field. The size-segregated aerosol was then introduced into the SMPS, recharged and scanned in a size range from 10 to $800 \mathrm{~nm}$. Additionally, the theoretical transfer functions including particle diffusion (Stolzenburg and McMurry (2008); Zhang and Flagan (1996)) for the sequential setup of the rDMA and the cylindrical DMA as described above are shown. The maxima of the calculated transfer functions lie within a maximum deviation of $0.7 \mathrm{~nm}$ of the geometric mean diameter calculated from the size distributions of the tandem DMA measurements. Differences between the measured distributions (Fig. 3a) and the theoretical transfer functions (Fig. 3b) are thought to be due to additional broadening in the real flow path through the rDMA and the SMPS's cylindrical DMA. As a result, the custombuilt rDMA is capable of separating quasi-monodisperse aerosol samples with a geometric standard deviation of about 1.09 in the relevant diameter range from $10-50 \mathrm{~nm}$ from ambient aerosol samples.

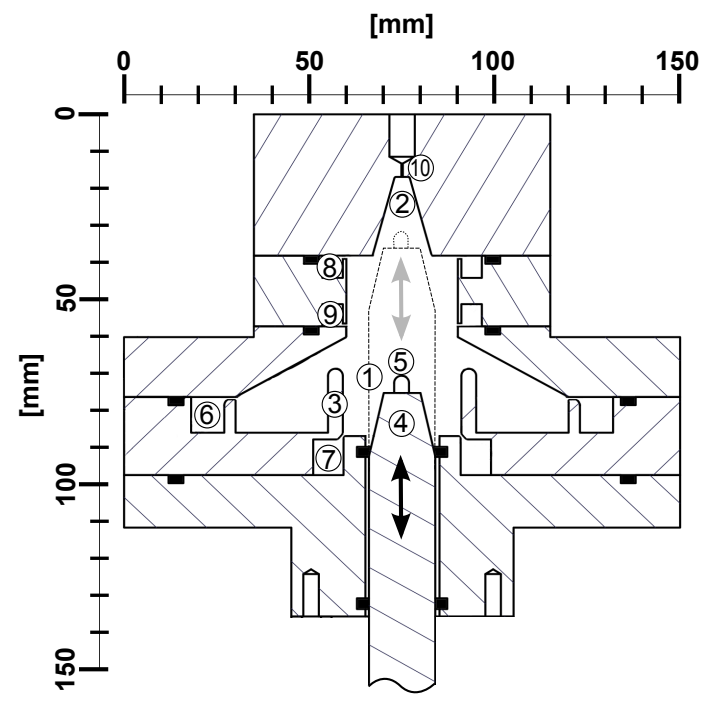

Fig. 4. Schematic of the radial collection and desorption unit with $\mathrm{NiCr}$ filament in collection position: (1) collection region, (2) desorption region, (3) collection tube, (4) PEEK piston, (5) collection filament, (6) aerosol inlet, (7) collection flushing inlet, (8) desorption flushing inlet, (9) exhaust and (10) screw connection for transfer capillary. Positions of O-rings are shown in black.

\subsection{Aerosol collection and desorption}

Exiting the rDMA, the size-segregated charged particles are introduced into the collection and desorption unit. Particles are collected on a high voltage $(3-5 \mathrm{kV})$ biased $\mathrm{NiCr}$ filament. The circular design (see Fig. 4 for details) can be divided into two distinct regions, i.e. (1) the collection region and (2) the desorption region. The collection region is composed of a collection tube (3) containing a movable PEEK (polyetheretherketone) piston (4) with the collection filament attached to its top (5). The collection tube is enclosed in a cylindrical housing. The sample flow with the charged particles is introduced between the collection tube and the housing via an annular gap (6) and extracted above (9). Due to the electric field originating from the collection filament, charged particles are directed towards the filament. For protection of the collected sample from contamination with gaseous constituents of the sample flow, the collection tube is permanently flushed with molecular nitrogen (7). A second nitrogen flow is introduced through an annular gap above (8), protecting the desorption region from contamination. The sample flow rate is set to 1 SLM while the collection region flushing flow rate (7) is set to $1.3 \mathrm{SLM}$, assuring that both flows have the same velocity at the upper edge of the collection tube. Both nitrogen flows and the sample flow are extracted through another annular gap (9) located above the collection tube.

During collection the filament is positioned below the upper edge of the collection tube. The collection efficiency for $25 \mathrm{~nm}$ particles is greater than $95 \%$ for $5 \mathrm{kV}$ applied 
to the filament and the mentioned flow rates. After collection, the PEEK piston is moved by means of a linear actuator towards the desorption region (2). The desorption chamber is a conical cavity made of aluminum with a volume of $0.4 \mathrm{~cm}^{3}$. The angles of the desorption chamber walls are chosen to fit the angles of the PEEK piston, providing that the chamber is sealed once the PEEK piston is pushed into the desorption position. Resistive heating of the collection filament allows temperature-controlled evaporation of the sample. The wire temperature is estimated based on the StefanBoltzmann law corrected with an optical temperature estimation through the wire's annealing color. The correction is necessary since the Stefan-Boltzmann law overestimates the temperature, only accounting for radiative heat transport. However, a considerable part of the heat is transported from the wire towards the connecting sockets as well as by convection to the surrounding gas phase.

In order to avoid condensational losses of the evaporated particles to the desorption chamber, the walls can be heated up to $200^{\circ} \mathrm{C}$. Finally, a heated, deactivated, fused silica capillary is connected to the upper part of the desorption region (10).

\subsection{Time-of-flight mass spectrometer}

The fused silica capillary with an inner diameter of $25 \mu \mathrm{m}$ transfers the desorbed gas sample to the TOF-MS. The capillary fulfills the tasks of transferring the sample directly to the ionization region in the TOF-MS, as well as ensuring the necessary pressure drop from the desorption region to the MS operating at a pressure of less than $1 \times 10^{-6}$ mbar. The mass spectrometer is a compact time-of-flight mass spectrometer (CTOF, Tofwerk AG, Thun, Switzerland). The compact, field-portable design yields a nominal mass resolving power of $800 \mathrm{Th}$ and a mass accuracy of better than $100 \mathrm{ppm}$. Standard $70 \mathrm{eV}$ electron ionization is applied resulting in fragmentation of the analytes. The fragmentation patterns are well known for many molecules, hence allowing a chemical interpretation of the mass spectra to a certain degree (Allan et al., 2004). Thus, the ionization method is a trade-off between high ionization efficiency and accurate compound identification. To enhance the potential for molecular identification, this CTOF is ready to be equipped with a soft photo ionization method in future studies. The mass spectrometer has a time resolution of $20 \mathrm{kHz}$, and typically one-second averages are written to hierarchical data format files (HDF5). Data analysis is performed with the Matlab-based toolbox tofTools, developed by H. Junninen (University of Helsinki).

\subsection{Experimental characterization}

To infer the detection performance of the mass spectrometer, a dilution series of an individual organic compound was measured. For this purpose, $1 \mu \mathrm{L}$ of camphene-ethanol dilutions of different concentrations were applied manually to the desorption filament by means of a $5 \mu \mathrm{L}$ syringe. After application, the filament was moved to the heated desorption region $\left(80^{\circ} \mathrm{C}\right)$ to desorb the sample for analysis in the TOFMS. Being a monoterpene, camphene $\left(\mathrm{C}_{10} \mathrm{H}_{16}\right)$ represents one of the major compound groups with oxidation products contributing to the growth of secondary particles. Its suitability for the dilution series is given by its solubility in ethanol and its solid state up to temperatures of about $51^{\circ} \mathrm{C}$, hence allowing its application to the filament without a significant loss of material prior to the desorption. The sum of the integrated peak areas of the major electron ionization fragments $(m / z, 93,121$ and 136) of camphene were used to obtain a robust signal from the mass spectrometer.

For further test and characterization purposes, laboratorygenerated secondary organic aerosol (SOA) was collected, desorbed and analyzed with CAChUP. SOA was produced with a laminar flow reactor (Reynolds number $R e=125$ ) for dark ozonolysis of alpha-pinene similar to Tolocka et al. (2006). The flow reactor consists of a glass tube with a length of $9 \mathrm{~cm}$ and a diameter of $1.2 \mathrm{~cm}$. The total volume of the reactor is $10 \mathrm{~cm}^{2}$. The volume flow rate through the flow reactor was set to $1.1 \mathrm{SLM}$, resulting in a residence time of about $0.5 \mathrm{~s}$. Alpha-pinene was introduced into the tube by passing a filtered zero air flow of 0.045 SLM over liquid alpha-pinene in a $100 \mathrm{~mL}$ flask. Ozone was generated by exposing a particle-free-airflow of 0.85 SLM to UV radiation produced by a Pen-Ray lamp. The ozone was introduced together with filtered air at a flow rate of 0.2 SLM. The alphapinene flow was introduced separately via a glass tubing in the center axis of the flow tube. The concentration of alphapinene in the tube was about $250 \mathrm{ppm}$, assuming saturation in the alpha-pinene flow at room temperature $\left(25^{\circ} \mathrm{C}\right)$ and accounting for the dilution with the other two flows. This value can be seen as an upper concentration limit since saturation was most likely not achieved. The ozone mixing ratio was $13 \mathrm{ppm}$ in the absence of alpha-pinene in the reactor measured using an ozone monitor (Model 49i, Thermo Scientific, Franklin, MA, USA). Despite the high concentration of ozone in the flow tube only a fraction of the gas-phase alphapinene was transformed to the particle phase. The aerosol flow still contained a considerable amount of gas-phase organics, as could be seen by turning off the two nitrogen purge flows, hence sampling with the mass spectrometer directly from the gas phase in the sample flow. About $90 \%$ of these gas-phase organics were removed by an activated charcoal denuder, installed between the flow tube and our instrument. The flow reactor setup resulted in a narrow particle-size distribution with a mean diameter of $31 \mathrm{~nm}$ and a geometric standard deviation of 1.33 .

\section{Results and discussion}

The instrument's detection performance for monoterpenes was deduced from a series of camphene-ethanol solutions of 


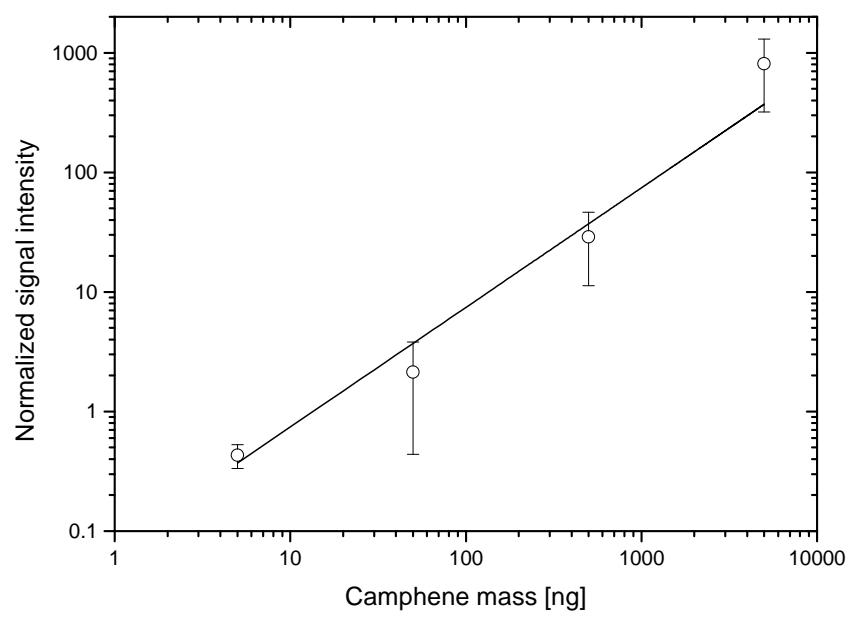

Fig. 5. Detection performance of the aerosol mass spectrometer for different camphene masses applied to the desorption filament. Normalized signal intensity equals the sum of the integrated peak areas of $m / z$ 93, 121 and 136 normalized with $m / z$ 207. Open cycles denote the mean signal intensity and the error bars show the standard deviation. A linear fit curve is shown to indicate the linearity of the signal.

different concentrations, as described above. From Fig. 5, a linear relation between the applied mass and the mass spectrometers signal intensity is evident. Shown is the normalized signal intensity of the sum of three electron ionization fragments of camphene $(\mathrm{m} / \mathrm{z} 93,121$ and 136). Evaporation of a $1 \mu \mathrm{L}$ droplet in the desorption chamber resulted in a considerable pressure increase in the mass spectrometer. This effect resulted in a sudden increase of the overall mass spectrometer's signal intensity. Therefore, a normalization of the data was performed by dividing the unit mass resolution sticks by the peak area of $m / z$ 207. Mass 207, being a typical contamination signal from silicone, was always visible in the measured mass spectra, showing variations only due to the mass spectrometer's operating conditions, like ionization efficiency and pressure changes. This mass is suitable for normalization because its signal strength is independent of the evaporation of the collected sample. Also shown in Fig. 5 are the standard deviations of the MS signal intensities. During the experiment pure ethanol as well as camphene masses of $0.5,5,50,500$ and $5000 \mathrm{ng}$ were applied to the filament. Both pure ethanol and the solution with $0.5 \mathrm{ng}$ camphene resulted in no clear signal from the TOF-MS. Figure 5 shows that a sample of $5 \mathrm{ng}$ of camphene yields a clear and quantitative signal. Thus, the detection limit for camphene is taken to be between 0.5 and $5 \mathrm{ng}$ with the present setup.

Figure $6 \mathrm{a}$ shows the procedure of the particle collection and blank experiments. Aerosol particles with a diameter of $25 \mathrm{~nm}$ were collected for time periods of $30 \mathrm{~min}, 1$ and $2 \mathrm{~h}$, and desorbed from the $\mathrm{NiCr}$ filament. During collection, the desorption chamber was continuously kept at $100^{\circ} \mathrm{C}$ and flushed with nitrogen. Also the filament was flushed

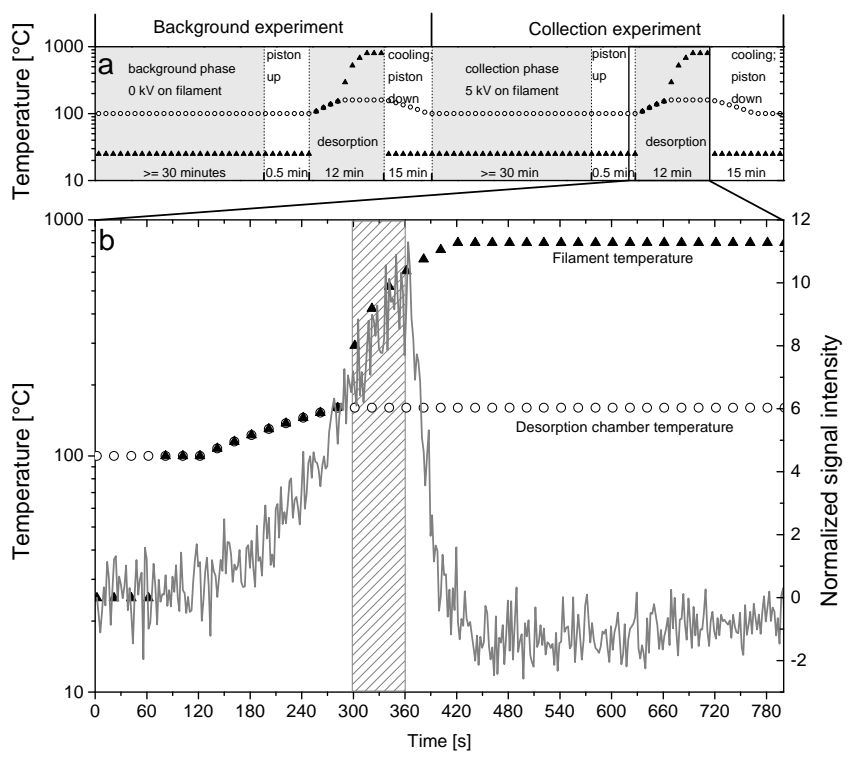

Fig. 6. (a) Sketch of the procedure for the background and collection experiments, with temperature courses of the desorption chamber (white circles) and the NiCr filament (black triangles). (b) Time evolution of the averaged signal from major organic peaks $(\mathrm{m} / \mathrm{z}$ $43,53,65,67,77$ and 91) during the desorption of oxidized alphapinene particles. The PEEK piston was in desorption position at second 60. Temperatures of the desorption chamber and the filament are also shown. The hatched area denotes the one-minute averaging period used for the mass spectrum shown in Fig. 7b.

with nitrogen, minimizing the collection of gas phase compounds and interactions of the collected sample with oxidants like ozone. Following the collection, the nitrogen flow is increased in order to flush the entire collection unit, preventing contamination during the travel period of the piston towards the desorption chamber. Once the piston reached its final position, the desorption chamber was heated from 100 to $160^{\circ} \mathrm{C}$. Only then was the $\mathrm{NiCr}$ filament heated gradually to its final temperature of about $800^{\circ} \mathrm{C}$ (see Fig. $6 \mathrm{~b}$ for details). The wire temperature was not directly measured, but estimated from the Stefan-Boltzmann law and by visual inspection of its annealing color. In Fig. $6 \mathrm{~b}$ the desorption process for the one-hour collection experiment is shown. Heating of the desorption chamber was initialized $60 \mathrm{~s}$ after the PEEK piston was moved to the desorption position. After $300 \mathrm{~s}$ the final desorption chamber temperature of $160^{\circ}$ was reached and the filament was heated from $\sim 300$ to $800^{\circ} \mathrm{C}$ during the next two minutes. Also shown in Fig. $6 \mathrm{~b}$ is the time evolution of the signal from averaged major peaks from the evaporated particles. The signal from the TOF-MS is clearly increasing due to the heating of the desorption chamber and reaching its maximum well before the filament reached its final temperature. Once the maximum was reached a steep decrease in the signal was observed, despite the persistent heating of the filament. It is remarkable that the signal seems less dependent 


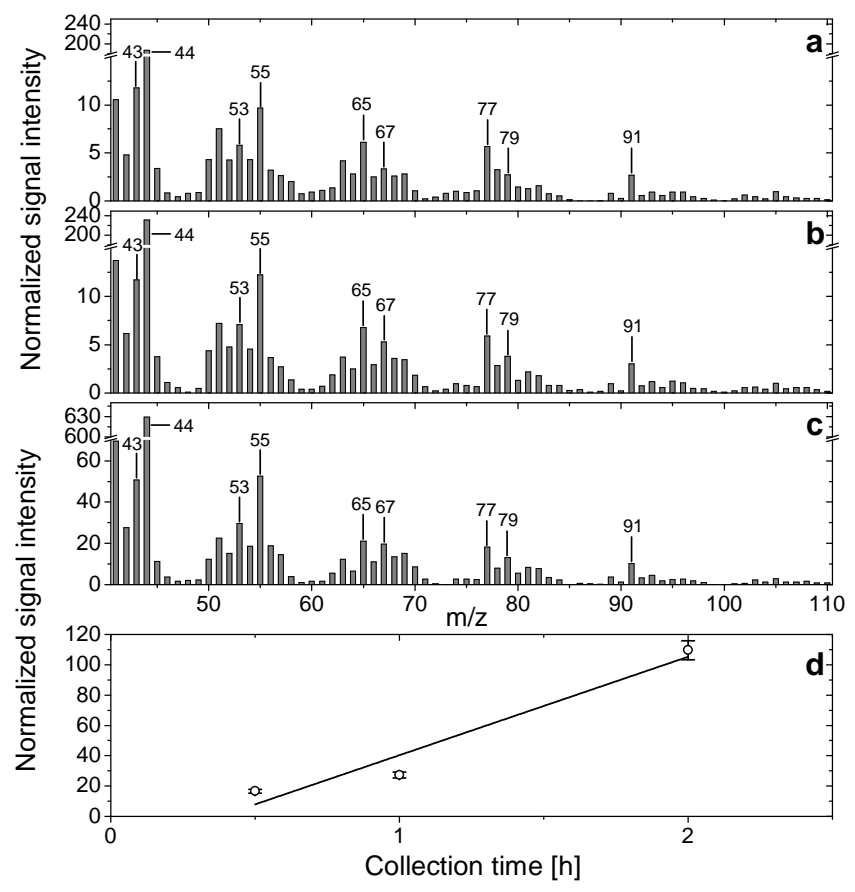

Fig. 7. Mass spectra of organic particles with a diameter of $25 \mathrm{~nm}$ from dark ozonolysis of alpha-pinene; (a), (b) and (c) are spectra after collection times of $0.5,1$ and $2 \mathrm{~h}$, respectively. The lower panel (d) shows the sum of the signal intensities of four major peaks $(\mathrm{m} / \mathrm{z}$ $55,65,77$ and 91) in relation to the collection time.

from filament heating than from the desorption chamber's temperature. The grey hatched area in Fig. $6 \mathrm{~b}$ indicates the averaging period from which the mass spectrum in Fig. $7 \mathrm{~b}$ was obtained. The one-minute averaging period was chosen for all experiments, always starting when the desorption current was applied to the $\mathrm{NiCr}$ filament.

Despite the activated charcoal denuder and the nitrogen purge flows, peaks of gas-phase organics were observed in the mass spectra. To prevent misinterpretation of the signal, a correction for potential gas-phase contamination is necessary. For this purpose, a blank measurement was performed, sampling the air without a high voltage applied to the collection filament, hence not collecting any particles. This correction is only possible if the adsorption of the gas-phase is similar during collection and blank measurement. This assumption is considered valid if the flow rates, temperatures and the duration of collection and desorption are kept constant for the regular and the blank measurement. A second reason for performing blank measurements is the condensation of evaporated particle compounds from the filament onto the desorption chamber walls. Even when the desorption region is heated to $200^{\circ} \mathrm{C}$, condensation of low volatile species cannot be ruled out when the filament is heated up to $800^{\circ} \mathrm{C}$. To account for temporal variations of the pressure in the mass spectrometer, the mass spectra were normalized. For normalization, the peak at $m / z 207$ was used, showing variations only due to the mass spectrometer's operating conditions, thus being independent of the desorbed sample.

Figure 7 shows mass spectra of three collection cycles with flow-tube-generated particles with a diameter of $25 \mathrm{~nm}$. During all three experiments, the basic conditions in the flow tube, the rDMA and the collection unit were kept constant. Only the collection time was varied between $0.5,1$ and 2 hours. For all three measurements, corresponding blank measurements were carried out. The presented mass spectra are consistent with published studies on laboratory-generated particles from ozonolysis of alpha-pinene (e.g. Chhabra et al., 2010; Shilling et al., 2009). In both studies highresolution time of flight aerosol mass spectrometers (HRTOF-AMS) with electron ionization were used. As CAChUP is also equipped with electron ionization, the general fragmentation patterns are expected to be comparable. For the three different collection periods, the signal intensities increase with longer collection times, while the ratios of the relative peak areas of the major peaks remain constant over the experiments. The major peaks in Fig. 7 are thought to be fragments of oxidized organics like $\mathrm{C}_{2} \mathrm{H}_{3} \mathrm{O}^{+}$for $m / z 43$, $\mathrm{CO}_{2}^{+}$for $m / z 44$ and $\mathrm{C}_{3} \mathrm{H}_{3} \mathrm{O}^{+} / \mathrm{C}_{4} \mathrm{H}_{7}^{+}$for $m / z 55$ (Chhabra et al., 2010; Shilling et al., 2009). Further prominent peaks are thought to be the non-oxidized ionization fragments $\mathrm{C}_{5} \mathrm{H}_{5}^{+}$, $\mathrm{C}_{6} \mathrm{H}_{5}^{+}, \mathrm{C}_{6} \mathrm{H}_{7}^{+}$and $\mathrm{C}_{7} \mathrm{H}_{7}^{+}$for $m / z 65,77,79$, and 91, respectively (based on Fig. 2 of Chhabra et al., 2010). The relation between the signal intensity and the collection time shown in Fig. 7d indicates higher signal intensities with longer collection times, and thus, more collected aerosol mass. The increase in signal with collection time is near to linearity, deviations could arise from slight variations in collection efficiency and particle numbers produced in the flow tube. Overall, the collection experiments show good performance of our instrument in flow tube experiments. The collection times can be extended to multi-hour periods and the use of a radioactive neutralizer is reasonable despite its poor charging efficiency, minimizing the contribution of multiply charged particles in the sample. In principle, CAChUP is ready for use in smog chamber experiments on the formation of SOA, either triggered by dark ozonolysis or photochemical reactions. Crucial for such experiments is the ability to produce particle formation events with similar growth rates that can be observed in the atmosphere. If the growth rates are too high, particles of a distinct diameter will not be present for a time period sufficient for collecting the necessary aerosol mass. Therefore, the concentration of gas phase precursors has to be chosen close to ambient concentrations yielding particles with a chemical composition comparable to atmospheric particles.

As described above, the detection limit of CAChUP for the dilution series of camphene is between $0.5 \mathrm{ng}$ and $5 \mathrm{ng}$. The detection performance of CAChUP during the flow tube experiments can only be determined roughly because the collected particle mass has to be estimated from particle 
concentration measurements with a CPC, attached downstream of the exhaust of the collection unit. Concentrations measured are to be regarded with care due to particle losses at the collection unit's exhaust and dilution with the nitrogen flows. The collection efficiency was estimated by calculating the concentration ratio between periods with a voltage applied to the collection filament and periods with no voltage applied. For particles with a diameter of $25 \mathrm{~nm}$ and $5 \mathrm{kV}$ applied to the filament, the collection efficiency was better than $95 \%$. The particle transmission through the collection unit was estimated by measuring the particle concentration upstream and downstream of the unit's sample inlet and outlet, respectively. Accounting for the dilution with the nitrogen purge flows the transmission was estimated to be between $81 \%$ and $100 \%$. Applying the corresponding collection and transmission efficiencies together with an assumed particle density of $1.25 \mathrm{~g} \mathrm{~cm}^{-3}$ (average estimate of the density values by Bahreini et al, 2005 and Kostenidou et al., 2007) and knowing the particle size and concentration as well as the aerosol volume flow through the collection unit, an estimate of the collected mass was obtained. For the three performed experiments, rough estimates of the collected masses were in the range of 2.1-2.6, 4.0-5.0 and 5.3-6.5 ng for the $0.5,1$ and $2 \mathrm{~h}$ experiments, respectively. Since collection times below $0.5 \mathrm{~h}$ did not result in quantitative signals from the mass spectrometer, the lower detection limit for the performed experiments is estimated to be below 2.1-2.6 ng, being in the same range as determined by the dilution series experiments. However, the detection limit will depend also on the composition of the collected particles. For example, for compounds experiencing less fragmentation by the mass spectrometer's electron ionization the detection could be substantially better.

The necessity for a sample of a few nanograms limits our present setup either to measurements of particles with diameters $>20 \mathrm{~nm}$ but relatively short collection periods, or particles $<20 \mathrm{~nm}$ with collection periods of several hours.

\section{Conclusions and outlook}

We have developed an aerosol mass spectrometer for the chemical analysis of particles with diameters below $30 \mathrm{~nm}$. The instrument collects a charged and sized particle sample on a metal filament. After collection the filament is resistively heated and the resulting gas phase is analyzed for its molecular composition in an electron ionization time of flight mass spectrometer. The functionality of the instrument has been validated in laboratory measurements by means of secondary organic particles produced from dark ozonolysis of alpha-pinene in a laminar flow tube, and by the direct application of known masses of camphene to the $\mathrm{NiCr}$ filament. Considering the results of these experiments, an application of CAChUP in the field seems to be feasible. For example, during nucleation events at the "Waldstein" ecosystem research site in the Fichtelgebirge mountain range, NE Bavaria,
Germany, particle concentrations with up to $90000 \mathrm{~cm}^{-3}$ were detected. During such events the concentration of particles with a diameter between $20 \mathrm{~nm}$ and $24 \mathrm{~nm}$ was found to be up to $4000 \mathrm{~cm}^{-3}$. Periods with elevated $20 \mathrm{~nm}$ particle concentrations $\left(>1000 \mathrm{~cm}^{-3}\right)$ prevailed for about $3 \mathrm{~h}$. Considering the charging efficiency of our unipolar charger, particle losses in the rDMA and the collection unit as well as the collection efficiency onto the $\mathrm{NiCr}$ filament during nucleation events, collected masses for $20 \mathrm{~nm}$ particles are expected to be in the order of $1 \mathrm{ng}$ to $7 \mathrm{ng}$, thus being within the estimated detection limit.

The performance of CAChUP is promising both for laboratory experiments and also for field measurements. Nevertheless, several improvements will further enhance the performance of the instrument. The unipolar charger is working, yet multiply charged particles still have to be avoided. With the present setup, this requires the use of a pre-impactor with a cut-off diameter at $50 \mathrm{~nm}$ or below. Multiple charges can also be avoided by charging the particles in a bipolar environment, although the charging efficiency will be small. In the past few years major advances towards bipolar corona discharge chargers have been accomplished (e.g. Stommel and Riebel, 2004). Further enhancement of the charged particle fraction could be accomplished by parallel use of multiple bipolar chargers coupled to an electrostatic-focusing device, focusing one polarity of charged particles to its center while extracting the excess air at its periphery. This way the concentration of charged particles could be enhanced significantly while keeping the same flow rate and collection efficiency in the collection unit. Finally, the flow regime inside the collection and desorption unit should be improved. Despite the permanent flushing of the $\mathrm{NiCr}$ filament and the desorption region, contaminations during the flow tube experiments could not be avoided completely, making it necessary to perform a blank measurement for every measurement conducted. As laboratory-generated, secondary organic particles will always be associated with a huge fraction of precursor molecules in the gas phase, the necessity of protecting the device from contaminations is crucial. To tackle this issue the collection unit must be optimized towards a flow regime with minimal turbulence, hence less penetration of the gas phase onto the $\mathrm{NiCr}$ filament and into the desorption region. Turbulence in the desorption region is assumed to be of greater importance due to the opposing direction of the $\mathrm{N}_{2}$ purge flow and the sample flow, as well as due to its enhanced surface compared to the filament. However, precursor gas phase contaminations are expected to be significantly smaller in the field than in our flow tube experiments.

CAChUP is now ready to be used both in laboratory and field experiments, and the described improvements will be implemented step by step for enhanced performance in future measurement campaigns. 
Acknowledgements. This work was supported by the German Research Foundation (DFG grant HE5214/3-1). We acknowledge for construction and technical support Thomas Braun, Klaus Burger, Andrej Einhorn, Stefan Feulner, Michael Groll and Heinz Krejtschi. For help and fruitful discussions we thank Sergej Bleicher, Otto Klemm, Britta Planer-Friedrich, Matthias Sörgel and Julian Wittmer, as well as Heikki Junninen for providing the evaluation software tofTools.

Edited by: H. Herrmann

\section{References}

Allan, J. D., Delia, A. E., Coe, H., Bower, K. N., Alfarra, M. R., Jimenez, J. L., Middlebrook, A. M., Drewnick, F., Onasch, T. B., Canagaratna, M. R., Jayne, J. T., and Worsnop, D. R.: A generalised method for the extraction of chemically resolved mass spectra from Aerodyne aerosol mass spectrometer data, J. Aerosol Sci., 35, 909-922, 2004.

Bahreini, R., Keywood, M. D., Ng, N. L., Varutbangkul, V., Gao, S., Flagan, R. C., Seinfeld, J. H., Worsnop, D. R., and Jimenez, J. L.: Measurement of secondary organic aerosol from oxidation of cycloalkenes, terpenes, and m-xylene using an Aerodyne aerosol mass spectrometer, Environ. Sci. Technol., 39, 5674-5688, 2005.

Barsanti, K. C., McMurry, P. H., and Smith, J. N.: The potential contribution of organic salts to new particle growth, Atmos. Chem. Phys., 9, 2949-2957, doi:10.5194/acp-9-2949-2009, 2009.

Chen, J. and Davidson, J. H.: Ozone production in the positive DC corona discharge: Model and comparison to experiments, Plasma Chem. Plasma P., 22, 495-522, 2002.

Chen, D. R. and Pui, D. Y. H.: A high efficiency, high throughput unipolar aerosol charger for nanoparticles, J. Nanopart. Res., 1, 115-126, 1999.

Chhabra, P. S., Flagan, R. C., and Seinfeld, J. H.: Elemental analysis of chamber organic aerosol using an aerodyne high-resolution aerosol mass spectrometer, Atmos. Chem. Phys., 10, 4111-4131, doi:10.5194/acp-10-4111-2010, 2010.

Delfino, R. J., Sioutas, C., and Malik, S.: Potential role of ultrafine particles in associations between airborne particle mass and cardiovascular health, Environ. Health Persp., 113, 934-946, 2005.

Forster, P., Ramaswamy, V., Artaxo, P., Berntsen, T., Betts, R., Fahey, D. W., Haywood, J., Lean, J., Lowe, D. C., Myhre, G., Nganga, J., Prinn, R., Raga, G., Schulz, M., and Dorland, R. V.: Changes in Atmospheric Constituents and in Radiative Forcing, in: Climate Change 2007: The Physical Science Basis, Contribution of Working Group I to the Fourth Assessment Report of the Intergovernmental Panel on Climate Change, edited by: Miller, H. L., Cambridge University Press, Cambridge, UK and New York, NY, USA, 129-234, 2007.

Han, B., Kim, H.-J., Kim, Y.-J., and Sioutas, C.: Unipolar charging of fine and ultra-fine particles using carbon fiber ionizers, Aerosol Sci. Tech., 42, 793-800, 2008.

Held, A., Nowak, A., Birmili, W., Wiedensohler, A., Forkel, R., and Klemm, O.: Observations of particle formation and growth in a mountainous forest region in central Europe, J. Geophys. Res., 109, D23204, 2004.

Held, A., Rathbone, G. J., and Smith, J. N.: A thermal desorption chemical ionization ion trap mass spectrometer for the chemical characterization of ultrafine aerosol particles, Aerosol Sci. Tech., 43, 264-272, 2009.

Kostenidou, E., Pathak, R. K., and Pandis, S. N.: An algorithm for the calculation of secondary organic aerosol density combining AMS and SMPS data, Aerosol Sci. Tech., 41, 1002-1010, 2007.

Kulmala, M., Vehkamäki, H., Petäjä, T., Dal Maso, M., Lauri, A., Kerminen, V.-M., Birmili, W., and McMurry, P. H.: Formation and growth rates of ultrafine atmospheric particles: a review of observations, J. Aerosol Sci., 35, 143-176, 2004.

Laaksonen, A., Kulmala, M., O’Dowd, C. D., Joutsensaari, J., Vaattovaara, P., Mikkonen, S., Lehtinen, K. E. J., Sogacheva, L., Dal Maso, M., Aalto, P., Petäjä, T., Sogachev, A., Yoon, Y. J., Lihavainen, H., Nilsson, D., Facchini, M. C., Cavalli, F., Fuzzi, S., Hoffmann, T., Arnold, F., Hanke, M., Sellegri, K., Umann, B., Junkermann, W., Coe, H., Allan, J. D., Alfarra, M. R., Worsnop, D. R., Riekkola, M.-L., Hyötyläinen, T., and Viisanen, Y.: The role of VOC oxidation products in continental new particle formation, Atmos. Chem. Phys., 8, 2657-2665, doi:10.5194/acp-82657-2008, 2008.

McMurry, P. H., Ghimire, A., Ahn, H. K., Sakurai, H., Moore, K., Stolzenburg, M., and Smith, J. N.: Sampling nanoparticles for chemical analysis by low resolution electrical mobility classification, Environ. Sci. Technol. 43, 4653-4658, 2009.

Otani, Y., Eryu, K., Furuuchi, M., Tajima, N., and Tekasakul, P.: Inertial classification of nanoparticles with fibrous filters. Aerosol Air Qual. Res., 7, 343-352, 2007.

Riipinen, I., Manninen, H. E., Yli-Juuti, T., Boy, M., Sipilä, M., Ehn, M., Junninen, H., Petäjä, T., and Kulmala, M.: Applying the Condensation Particle Counter Battery (CPCB) to study the water-affinity of freshly-formed 2-9 $\mathrm{nm}$ particles in boreal forest, Atmos. Chem. Phys., 9, 3317-3330, doi:10.5194/acp-9-33172009, 2009.

Shilling, J. E., Chen, Q., King, S. M., Rosenoern, T., Kroll, J. H., Worsnop, D. R., DeCarlo, P. F., Aiken, A. C., Sueper, D., Jimenez, J. L., and Martin, S. T.: Loading-dependent elemental composition of $a$-pinene SOA particles, Atmos. Chem. Phys., 9, 771-782, doi:10.5194/acp-9-771-2009, 2009.

Smith, J. N., Moore, K. F., McMurry, P. H., and Eisele, F. L.: Atmospheric measurements of sub-20 nm diameter particle chemical composition by thermal desorption chemical ionization mass spectrometry, Aerosol Sci. Tech., 38, 100-110, 2004.

Smith, J. N., Barsanti, K. C., Friedli, H. R., Ehn, M., Kulmala, M., Collins, D. R., Scheckman, J. H., Williams, B. J., and McMurry, P. H.: Observations of aminium salts in atmospheric nanoparticles and possible climatic implications, P. Natl. Acad. Sci. USA, 107, 6634-6639, 2010.

Stieb, D. M., Judek, S., and Burnett, R. T.: Meta-analysis of timeseries studies of air pollution and mortality: effects of gases and particles and the influence of cause of death, age, and season, JAPCA J. Air Waste Ma., 52, 470-484, 2002.

Stolzenburg, M. R. and McMurry, P. H.: Equations governing single and tandem DMA configurations and a new lognormal approximation to the transfer function, Aerosol Sci. Tech., 42, 421-432, 2008.

Stommel, Y. and Riebel, U.: A new corona discharge-based aerosol charger for submicron particles with low initial charge, J. Aerosol Sci., 35, 1051-1069, 2004.

Tolocka, M. P., Heaton, K. J., Dreyfus, M. A., Wang, S., Zordan, C. A., Saul, T. D., and Johnston, M. V.: Chemistry of particle 
inception and growth during $\alpha$-pinene ozonolysis, Environ. Sci. Technol., 40, 1843-1848, 2006.

Voisin, D., Smith, J. N., Sakurai, H., McMurry, P. H., and Eisele, F. L.: Thermal desorption chemical ionization mass spectrometer for ultrafine particle chemical composition, Aerosol Sci. Tech., 37, 471-475, 2003.

Wang, S., Zordan, C. A., and Johnston, M. V.: Chemical characterization of individual, airborne sub-10-nm particles and molecules, Anal. Chem., 78, 1750-1754, 2006.

Wiedensohler, A.: Technical note: an approximation of the bipolar charge distribution for particles in the submicron size range, J. Aerosol Sci., 19, 387-389, 1988.
Winkler, P. M., Ortega, J., Karl, T., Cappellin, L., Friedli, H. R., Barsanti, K., McMurry, P. H., and Smith, J. N.: Identification of biogenic compounds responsible for size-dependent nanoparticle growth, Geophys. Res. Lett., 39, L20815, 2012.

Zhang, S.-H. and Flagan, R. C.: Resolution of the radial differential mobility analyzer for ultrafine particles, J. Aerosol Sci., 27, 1179-1200, 1996.

Zhang, S.-H., Akutsu, Y., Russell, L. M., Flagan, R. C., and Seinfeld, J. H.: Radial differential mobility analyzer, Aerosol Sci. Tech., 23, 357-372, 1995. 